Research Paper

\title{
Selective Accumulation of Th2-skewing Immature Erythroid Cells in De- veloping Neonatal Mouse Spleen
}

\author{
Mercedes R. Rincon ${ }^{1,3}$, Karen Oppenheimer², Elizabeth A. Bonney2,3, $₫$ \\ 1. University of Vermont College of Medicine Department of Medicine/Immunobiology; \\ 2. University of Vermont College of Medicine Department of Obstetrics, Gynecology, and Reproductive Sciences; \\ 3. The Vermont Center for Immunology and Infectious Diseases, 89 Beaumont Avenue, Burlington, Vermont, USA, 05405.
}

Corresponding author: Elizabeth A. Bonney, Given Building Room C-246, 89 Beaumont Avenue, Burlington, Vermont, 05405; (802) 656- 8677; Fax (802) 656-8771; email: ebonney@uvm.edu.

(c) Ivyspring International Publisher. This is an open-access article distributed under the terms of the Creative Commons License (http://creativecommons.org/ licenses/by-nc-nd/3.0/). Reproduction is permitted for personal, noncommercial use, provided that the article is in whole, unmodified, and properly cited.

Received: 2011.11.07; Accepted: 2011.12.16; Published: 2012.05.16

\begin{abstract}
Environmental factors likely regulate neonatal immunity and self-tolerance. However, evidence that the neonatal immune system is suppressed or deviated is varied depending on the antigen and the timing of antigen exposure relative to birth. These disparate findings may be related to the availability of the appropriate antigen presenting cells but also point to the possibility of homeostatic changes in non-lymphoid cells in the relevant lymphoid tissues. Here we show that, while leukocytes are the most abundant cell population present in spleen during the first 4-5 days after birth, a massive accumulation of nucleated immature erythroid population in the spleen takes places on day 6 after birth. Although the relative frequency of these immature erythorid cells slowly decreases during the development of neonates, they remain one of the most predominant populations up to three weeks of age. Importantly, we show that the immature erythroid cells from neonate spleen have the capacity to modulate the differentiation of CD4 T cells into effector cells and provide a bias towards a Th2 type instead of ThI type. These nucleated erythroid cells can produce cytokines that participate in the Th2/ThI balance, an important one being IL- 6 . Thus, the selective accumulation of immature erythroid cells in the spleen during a specific period of neonatal development may explain the apparent differences observed in the type(s) of immune responses generated in infants and neonates. These findings are potentially relevant to the better management of immune deficiency in and to the design of vaccination strategies for the young.
\end{abstract}

Key words: Neonatal immunity, erythrocytes, T lymphocytes.

\section{Introduction}

Although the global mortality rate has fallen, nearly eight million children under five die each year, and the two biggest killers of these children are infectious diseases [1]. The cost of hospitalization for infected infants in the United States alone is estimated at 690 million dollars annually [2]. While most vaccines do induce protective immunity in older children and adults, their efficacy in the very young often requires further manipulation and optimization. This im- portant clinical phenomenon suggests that further examination of the immune physiology of the young is required.

Since the articulation of Lederberg's [3] immune theory, common thinking is that the immune response in neonates differs from that found in adults. Although evidence exists to support this idea the underlying mechanism(s) remain unclear. Initially, it was thought that neonatal $\mathrm{T}$ cells were intrinsically 
deficient (e.g. prone to apoptosis) [4]. However, there exist studies [5] which show that by supplying the correct form of antigen presentation (e.g. activated dendritic cells) neonatal mice could produce effective immune responses even to minor antigens. More recently [6] it was found that DNA vaccination of neonates produced good immunity to Lymphocytic choriomeningits virus (LCMV). Concurrent with the development of ideas about the relevance of the type (i.e., Th1,Th2,) of immune response [7], studies were generated suggesting that neonates were able to respond to antigen, but with a Th2-type bias [8-10]. A review of the literature with a focus on the timing of antigen exposure reveals that there are studies indicating that administration within the first 24 hours after birth tends to produce Th1 type of immune responses [5, 6, 11-17]. However, primary exposure to antigen when neonates are 5 days to two weeks old leads to a predominant Th2-type of immune response [9],[18]. The Th2 bias was observed primarily in spleen, but not lymph nodes [16]. With the advent of the Th17 response in common immunological dialogue [19], it has also been suggested that there are times, at least in early postnatal human development where this type of response might be either enhanced or suppressed [20]. Together these studies appear to indicate that the timing of exposure during neonatal development as well as the route of exposure is essential for determining the type of immune response in neonates.

In this study we identify an unusual cell type that massively accumulates in the spleen of neonates several days after birth. We show that nucleated immature erythroid cells represent the predominant population of the spleen of neonates starting from day 6 . These cells have the capacity to secrete specific cytokines (e.g. IL-6) and can modulate differentiation of CD4 T cells to favor the development of a Th2 type of immune response. Thus, the presence of immature erythroid cells in the spleen during a specific period of neonatal development could have implications in the immune response to infections or immunizations.

\section{Materials and Methods}

\section{Mice and tissues}

Animals were used in accordance with the Institutional Animal Care and Use Committee (IACUC) at the University of Vermont. Eight to ten week old C57BL/6 (B6) mice were purchased from The Jackson Laboratory (Bar Harbor, ME) and maintained under specific pathogen free conditions at the University of Vermont. The mice underwent a timed mating and observed for delivery of a litter. The morning after a litter delivered was considered day one of postnatal life. At 2 through 42 days of life the pups were euthanized and their spleen used for the studies described. Mice at 21 days of postnatal life were weaned.

\section{Flow cytometry}

In order to identify specific erythroid and immune cell populations by flow cytometry we used a panel of monoclonal antibodies against cell surface proteins that are generally accepted to characterize each cellular subset. Erythroid precursors were distinguished by the presence of the lymphocyte antigen 76 (LY-76, TER-119) molecule, which is found on the red cell surface from the pro-erythroblast to the mature erythrocyte stage [21]. Throughout development B lymphocytes selectively express the protein tyrosine phosphatase receptor type C (PTPRC, B220) protein, a glycosylated high molecular weight splice variant of the common leukocyte antigen $[22,23]$. The $\mathrm{T}$ cell receptor beta chain (TCRB) is one component of the T cell antigen receptor signaling complex [24] that is expressed exclusively on the surface of alpha/beta $\mathrm{T}$ lymphocytes [25]. The lymphocyte antigen 6 complex, locus G (LY-6G, GR1) protein is expressed predominantly by neutrophils in peripheral tissues as well as on the cell surface of granulocytes in the bone marrow [26]. Cells of the monocyte/macrophage lineage can be characterized by expression of integrin alpha M (ITGAM, CD11b) [27]. Tissue resident macrophages in the spleen that are $\mathrm{CD} 11 \mathrm{~b}$ positive express genes involved in chemotaxis and bacterial degradation, while CD11b negative cells express genes involved in phagocytosis and iron recycling [28]. Monoclonal antibodies against these cell types were obtained from eBioscience, Inc., San Diego, CA and BD Biosciences, San Jose, CA.

\section{Quantitative PCR}

Total RNA was extracted from sorted cell samples using Triazol (Invitrogen) per manufacture's guidelines. RNA samples were tested for integrity using the Agilent Bioanalyzer (Agilent Technologies). All samples were quantified by UV absorbance at 260 $\mathrm{nm}$ on a nanodrop spectrophotometer (NanoDrop, ThermoScientific, Willmington, DE). Real time RT-PCR studies were performed in a two-step process. The iScript cDNA synthesis kit (Bio-Rad Laboratories, Hercules, CA) was used to synthesize cDNA from 250ng (T-cells), or 750ng (Terr119 cells) of RNA template using a mix of random hexamers and oligo dts. For each sample the cDNA was used to amplify the target genes, including cytokines interleukins-2, 4, 6 and interferon- $\gamma$. In addition, primer sets were designed to determine the expression of the hemoglobin 
adult major chain (Hbb-b1) [29] and the hemoglobin Z, beta-like embryonic chain (Hbb-bh1) [30] as an estimate of the relative expression of adult and fetal hemoglobin by Ter $119^{+}$cells. The expression of two housekeeping genes hypoxanthine guanine phosphoribosyl transferase 1 (Hprt1) and tyrosine 3-monooxygenase/ tryptophan 5-monooxygenase activation protein, zeta polypeptide (Ywhaz) was also included in these studies. One microliter of cDNA was used per reaction with $150 \mathrm{nM}$ of the forward and reverse primers (see table 1), and 12.5ul of Power Sybrgreen Master Mix (Applied Biosystems) in a $25 \mu \mathrm{l}$ reaction. The reactions were performed on an $\mathrm{ABI}$ Prism 7000 (Applied Biosystems) using an initial denaturation of 10 minutes at $95^{\circ} \mathrm{C}, 40$ cycles of 15 seconds at $95^{\circ} \mathrm{C}$ and 60 seconds at $60^{\circ} \mathrm{C}$, followed by a melt curve analysis to ensure only the correct product was amplified. Standard curves were generated for all the target genes as well as the housekeeping genes using a single sample which was serially diluted over the working range of the assay. Using these standard curves the relative quantities of each sample were determined. Relative target mRNA values were normalized by dividing the target quantity by the geometric mean of the quantities of the housekeeping genes. Each sample was run in triplicate and averaged. Negative water controls were run for each primer set in the real time PCR reaction to ensure no contamination in the reagents as well as no secondary primer structures were amplified. In each primer set at least one primer was designed over an exon-exon junction or if that was not possible, the primers spanned an intron region. The specific primers used are seen in Table 1.

\section{Cell culture}

$\mathrm{CD}^{+} \mathrm{T}$ cells from lymph nodes and spleens were isolated by negative selection, as previously described depleting cells expressing CD8, CD11b, MHC class II, and NK1.1 [31]. $\mathrm{CD}^{+} \mathrm{T}$ cells were activated with plate-bound $5 \mu \mathrm{g} / \mathrm{ml}$ anti-CD3 (2C11) and $1 \mu \mathrm{g} / \mathrm{ml}$ of soluble anti-CD28 (BD) mAbs in Bruff's medium in the presence or absence of different amounts of Ter $119^{+}$cells. Ter $119^{+}$cells were purified using a magnetic bead system as per the manufacturer's instructions (Miltenyi, Auburn CA).

\section{ELISA}

ELISAs were performed as previously described [32] with purified anti-IL-2, anti-IFN $\gamma$, anti-IL-4 and anti-IL-6 mAb $(2 \mu \mathrm{g} / \mathrm{ml})$ as capture antibody. For the revelation step the corresponding biotinylated anti-IL-4, anti-IL-2, anti-IFN $\gamma$ and anti-IL-6 mAb (1 $\mu \mathrm{g} / \mathrm{ml}$; BD PharMingen), were used with horseradish peroxidase-conjugated streptavidin (Sigma-Aldrich), and TMB microwell peroxidase substrate and stop solution (Kirkegaard \& Perry Labs, Inc.) according to the manufacturer's instruction (BD PharMingen).

Table I. Primers used for the Quantitative PCR studies described.

\begin{tabular}{|c|c|c|}
\hline Name & Sequence & Product size \\
\hline$H b b$-bh1(fetal hgb)_Forward & GTTAAGAACATGGACAACCTCAAGGA & 127 \\
\hline Hbb-bh1_Reverse & GAGTAGAAAGGACAATCACCAACATG & \\
\hline Hbb-b1(adult hgb)_F & ACGCCGATGAAGTTGGTGGT & 110 \\
\hline$H b b-b 1 \_\mathrm{R}$ & CATGATAGCAGAGGCAGAGGATAGG & \\
\hline IL2_F & CCCAGGATGCTCACCTTCAAATT & 96 \\
\hline IL2_R & ATGCCGCAGAGGTCCAAGTT & \\
\hline IL4_F & CCACGGATGCGACAAAAATCA & 157 \\
\hline IL4_R & CACCTTGGAAGCCCTACAGAC & \\
\hline IL6_F & AGAAAGACAAAGCCAGAGTCCTTCAG & 157 \\
\hline IL6_R & GTCCTTAGCCACTCCTTCTGTGACT & \\
\hline If $n \gamma_{-} \mathrm{F}$ & CCTCATGGCTGTTTCTGGCTGTTA & 359 \\
\hline Ifn $\gamma_{-} \mathrm{R}$ & CATTGAATGCTTGGCGCTGGACC & \\
\hline Hprt_F & CAGTCCCAGCGTCGTGAT & 137 \\
\hline Hprt_R & CAAGTCTTTCAGTCCTGTCCATAA & \\
\hline Ywhaz_F & GCA ACG ATG TAC TGT CTC TTT TGG & 149 \\
\hline Ywhaz_R & GTCCACAATTCCTTTCTTGTCATC & \\
\hline
\end{tabular}




\section{Results}

\section{Selective accumulation of immature erythro- blasts in the spleen from neonates acquired after birth}

Although it is believed that spleen cellularity in neonates is different from that in adults, no studies have completely characterized the populations present during maturation in the neonatal period. We therefore examined neonatal spleen cells by flow cytometry. The presence of leukocytes (i.e. lymphocytes, macrophages, granulocytes, dendritic cells, natural killer cells and others) was determined by detecting the expression of the pan-leukocyte marker CD45. The majority of cells in spleen of day-2 neonates (Figure 1A) were $\mathrm{CD}_{4} 5^{+}$cells. Interestingly, however, the proportion of $\mathrm{CD}_{4} 5^{+}$spleen cells drastically dropped by day 6 and remained low during most of the neonatal stage. It slowly increased again by day 15 after birth. The non-leukocyte population that emerged 6 days after birth and accumulated in the spleen expressed CD44, although at lower levels than most leukocytes (Figure 1A). To initiate the characterization of this non-leukocyte population of cells present in the neonatal spleen, we performed histological analysis by Giemsa staining of cytospun cells from the spleen of adult mice or day- 8 and day- 17 neonates. As expected, in adult spleen almost all cells were small, displayed a condense nucleus that occupied most of their cell content, and have minimal cytoplasm content (Figure 1B). In contrast, the spleen cells from day-8 neonates were substantially larger, with less a condensed nucleus and increased cytoplasmic area suggestive of early hematopoietic progenitors present in bone marrow. Consistent with the presence of non-leukocyte cells observed by flow analysis, these large cells remained in the spleen of day-17 neonates, although their frequency was observed to be much lower than at day 8 (Figure 1B). A.

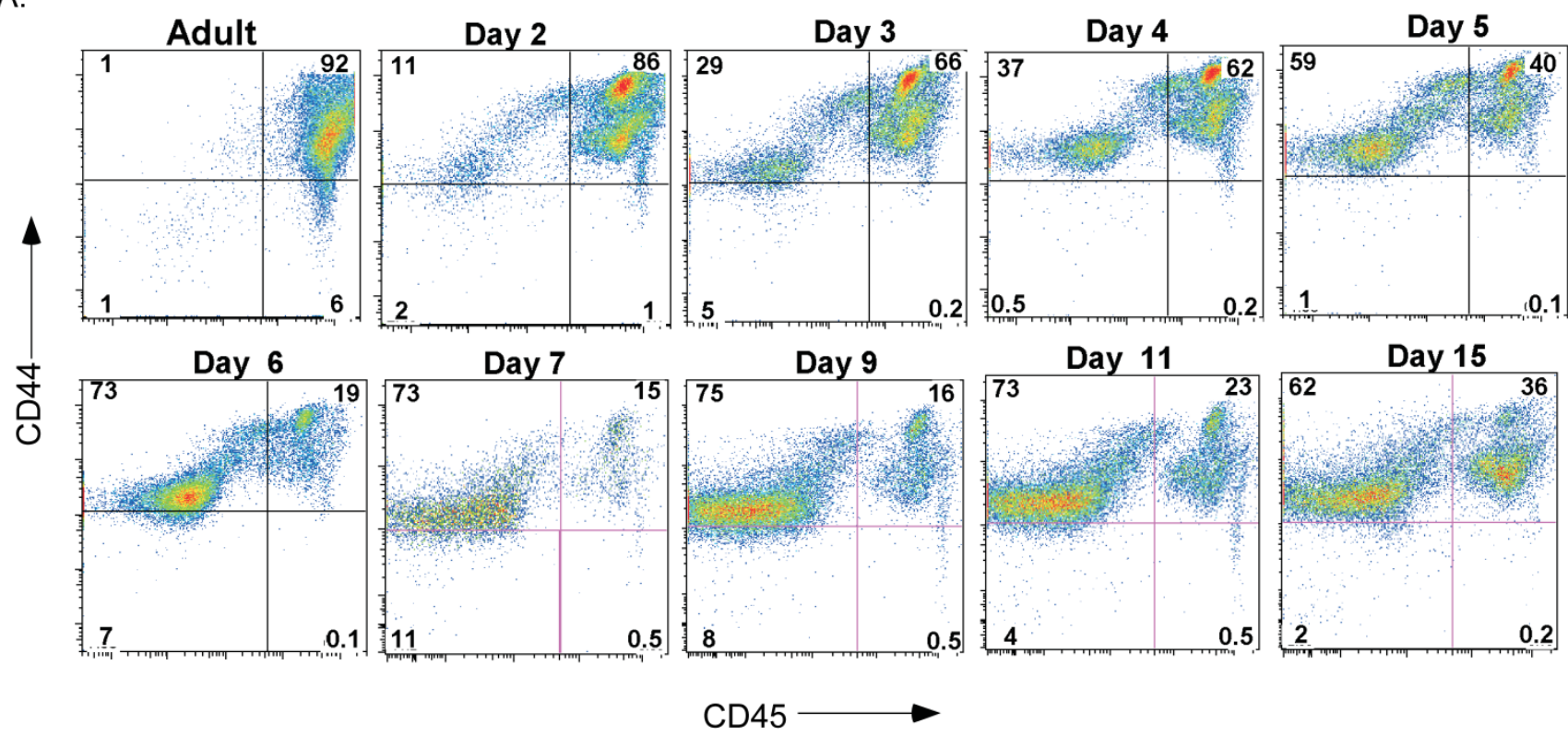

B.

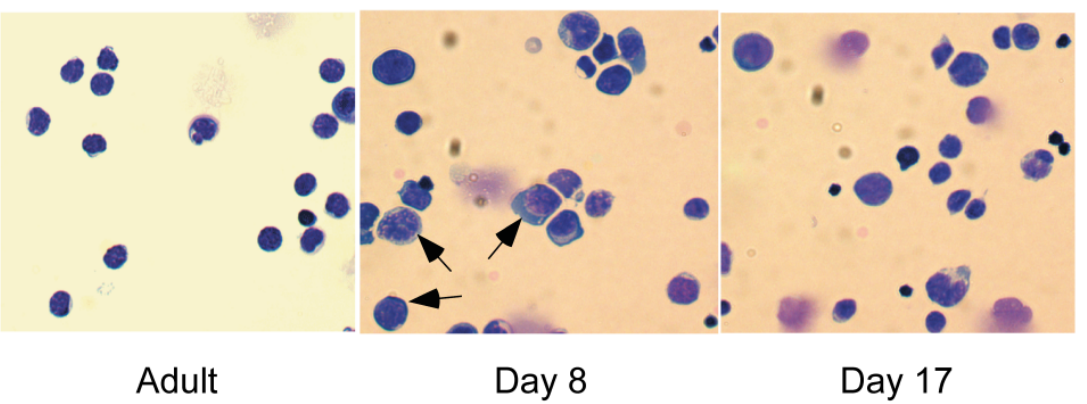

Figure I. Presence of a non-lymphoid population of cells in neonatal spleen after 6 days of birth. A. Flow cytometric analysis of CD44 and CD45 in spleens from adult mice and neonates at different periods of time after birth. Numbers represent the percentage of cells in each quadrant. B. Giemsa staining of cytospun spleen cells from adult mice and day-8 and day- 17 neonates. Arrows point to large cells with less condensed nuclei. Data shown are representative of three experiments. 
A.

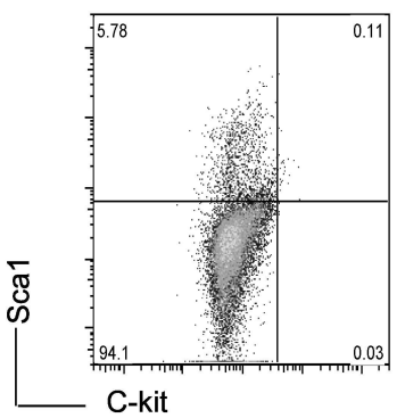

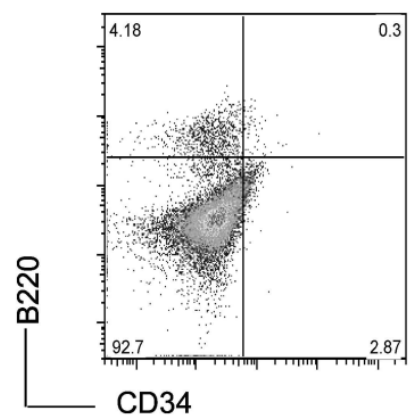

riguit

B.
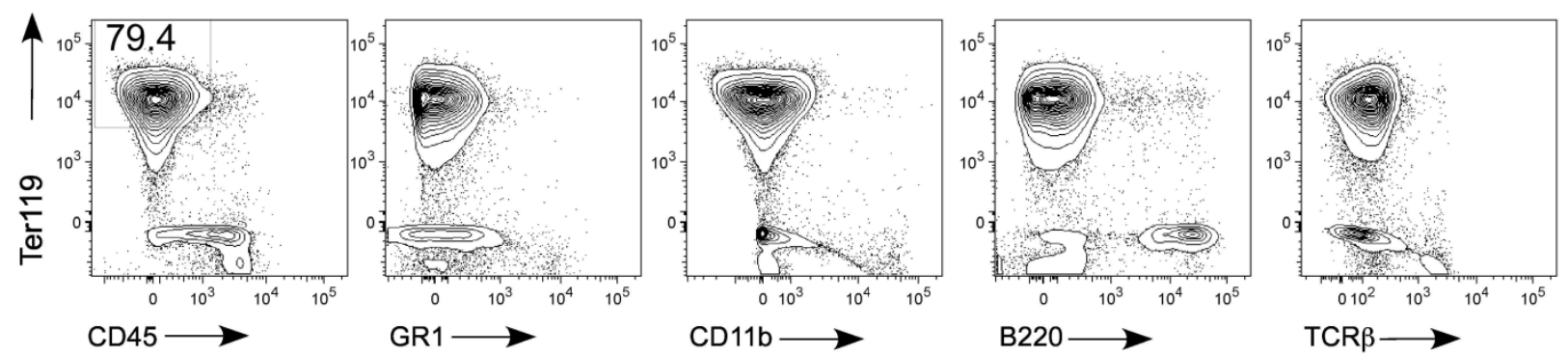

C.

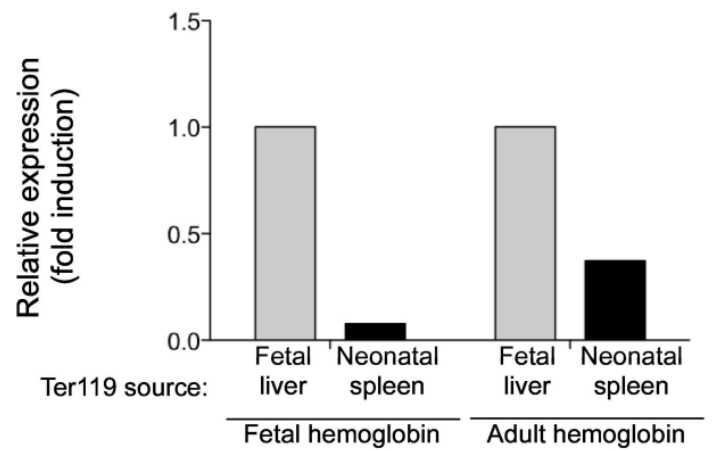

Figure 2. Phenotype of Terl I9+ immature erythroid cells in neonatal spleen. A. Flow cytometry analysis for Sca I, C-kit, B220 and CD34 in spleen from day-7 neonates. Numbers represent the percentage of cells in each quadrant. B. Flow cytometry analysis for Terl 19 together with CD45, Ly6G/C (Grl), CDI Ib, B220 and TCR $\beta$. Numbers represent the percentage in each gated population. Data from $A$ and $B$ are representative of three experiments. $C$. Expression of fetal and adult hemoglobin in Ter I I9+ cells isolated from the liver of three day- 17 fetuses (fetal liver) and from spleens of three day-6 neonates (neonatal spleen) by RT-PCR using total RNA. Values are expressed as fold induction relative to the expression in fetal liver Terl I 9 cells.

This atypical population of large cells was not abundant for the first 3-4 days after birth (data not shown) arguing that they were not fetal-derived early progenitors. Nevertheless, we examined whether they could be hematopoietic stem cells migrating from bone marrow. No CD34+ multipotent stem cells [33] were detected in spleen from day-7 neonate mice (Figure 2A). Similarly, we could not detect C-kit ${ }^{+}$ $\mathrm{Sca}^{+}$cells $[34,35]$, that are normally present in bone marrow, in this population of spleen cells.

The morphology of these non-leukocyte cells also resembled the histological prototype of erythrocyte precursors. The antigen Ter119 is associated with glycophorin A on the surface of immature or matur- ing erythrocytes [21], but not blast forming or colony forming units or erythro-leukemias. Therefore, we examined the presence of Ter $119^{+}$cells in spleen from day-7 neonates. Mature peripheral blood red blood cells were first lysed from the spleen cell homogenate. Interestingly, we observed that most of the non-leukocyte population (CD45- cells) was Ter-119+ (Figure 2B). Further, these cells did not express the markers for the myeloid lineage (Gr1 and CD11b), T cell lineage (TCR $\beta)$ or B cell lineage (B220) (Figure 2B). To demonstrate that this population represents immature erythroid cells generated after birth, we assessed the presence of fetal and adult hemoglobin. Ter $119^{+}$cells were isolated from day-17 fetal liver and 
from the spleen of day-7 neonates. Relative to fetal liver Ter119+ cells, almost no expression of fetal hemoglobin was detected in Ter119 cells from spleen of day-7 neonates (Figure 2C). They however expressed adult hemoglobin, but to a lower level compared with the fetal liver Ter119+ cells (Figure 2C). Taken together, these data identify the accumulation of an immature erythroid population in the spleen of neonates that is likely not derived from fetal hematopoiesis and is generated several days after birth.

\section{The accumulation of immature erythroid cells compromises the presence of lymphocytes in spleen of neonates.}

To more carefully document the kinetics for accumulation of the immature erythroid cells in neonatal spleen over the time of development, we collected spleen cells at regular intervals from 2 days after birth to 3 weeks after weaning. We further confirmed that a major accumulation of these cells in the spleen occurs between days 6 and 8 after birth (Figure 3A). Thereafter they slowly decreased but even at weaning age they comprised a higher proportion of the spleen than that found in adult spleen ( 5 weeks of age). The window for the accumulation peak of Ter119 cells in spleen and their further disappearance was consistent among different littermates and different experiments (Fig. 3B).

The expansion and contraction of a discreet non-lymphoid cell population in the spleen may alter the environment for the development of immune cells in that tissue, particularly if these cells compete for nutrients or other resources. When we examined the kinetics of other lymphoid cell populations in the spleen during neonatal life, we found that both CD4 and CD8 $\mathrm{T}$ cells remain a minority population from early after birth to weaning age (Figure 3C and 3E). The expansion of $\mathrm{T}$ cells at this stage correlated with the contraction of the nucleated Ter $119^{+}$population (Figure 3A and 3B). Interestingly, unlike T cells, the B cell population is highly represented early after birth (days 2-4) (Figure 3D). However, it drastically contracted at day 5-6 after birth in correlation with the expansion of the erythroid cell population, and expanded again- also correlating with the contraction of the erythroid cell population (Figure 3D). Thus the transient but rapid accumulation of the immature erythroid population compromises and/or limits the presence of $\mathrm{T}$ and $\mathrm{B}$ cells in the spleen in neonates. We also observed neutrophils to be the second (after B cells) most abundant cell lineage in spleen early after birth (days 2-4) as determined by flow cytometry analysis $\left(\mathrm{Gr}^{+} \mathrm{CD}^{+1 b^{+}}\right)$(Figure 3F) and by Giemsa staining (data not shown). The presence of neutro- phils in the spleen of neonates is rapidly terminated with the arrival of the immature erythroid cells. These data further suggest that the accumulation of erythroid cells in the spleen of neonates may also affect the innate immune system.

\section{Immature erythroid cells present in the neo- natal spleen have the ability to regulate acti- vation and effector function of CD4 T cells.}

By the current paradigm, CD4 $\mathrm{T}$ cell activation and differentiation is regulated primarily by antigen presenting cells that provide not only the specific antigens but also the right cytokine milieu. However, cells other than immune cells could also contribute to shaping CD4 $\mathrm{T}$ cell responses if present in sufficient amount. Since the data above show the presence of a large frequency of immature erythroid cells in the spleen of neonates, these cells could also modulate the CD4 T cell response. To test this hypothesis purified CD4 T cells from adult mice were activated with anti-CD3 and anti-CD28 monoclonal antibodies (Abs) in the absence or presence of purified immature erythroid cells (nucleated Ter119+ cells) from spleen of day-6 neonates. After three days of differentiation, CD4 T cells were harvested and extensively washed. No Ter $119^{+}$cells remained alive at this time (data not shown). Equal numbers of CD4 $\mathrm{T}$ cells were then re-stimulated with anti-CD3 Ab for 24 hours. Cytokine levels in the culture supernatants were determined by ELISA. The presence of Ter119 cells during differentiation prevented the production of IL-2 by effector CD4 $\mathrm{T}$ cells (Figure 4A, top panel). The Ter119 cells also compromised the production of IFN $\gamma$ by effector CD4 $\mathrm{T}$ cells (Figure 4A, middle panel). Since both of these cytokines have been grouped as Th1-type cytokines, we also examined IL-4 levels as a marker for Th2 effector cells. Interestingly, IL-4 production by $\mathrm{CD} 4 \mathrm{~T}$ cells differentiated in the presence of Ter119+ cells was not reduced but enhanced (Figure $4 \mathrm{~A}$, bottom panel). Since the difference in cytokines in the culture supernatants could also be due to an increased or decreased uptake of cytokine, we examined cytokine gene expression by quantitative reverse transcriptase (RT)-PCR in effector CD4 $\mathrm{T}$ cells that were differentiated in the presence or absence of Ter119+ cells. Correlating with the cytokine levels in culture supernatant, Ter $119^{+}$cells caused a downregulation of IL-2 and IFN $\gamma$ gene expression, and an up-regulation of IL-4 gene expression (Figure 4B). Thus, the presence of immature erythroid cells during the antigen stimulation of CD4 T cells can influence the type of cytokine produced as effector cells, with a bias towards Th2-type cytokines. 


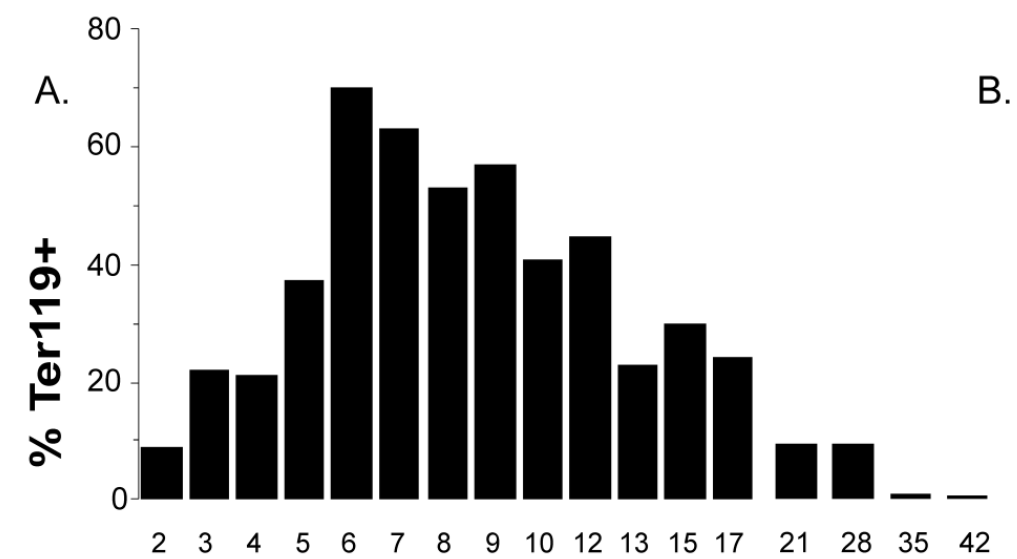

B.

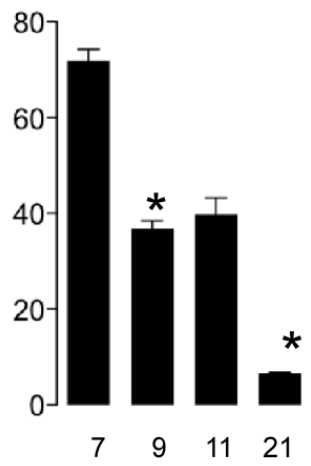

day

C.

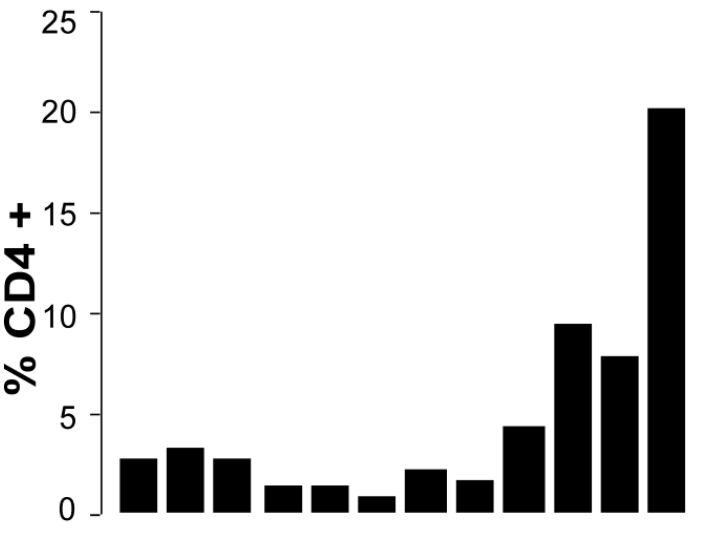

$\begin{array}{llllllllllll}2 & 3 & 4 & 5 & 6 & 7 & 10 & 13 & 21 & 28 & 35 & 42\end{array}$
D. 60

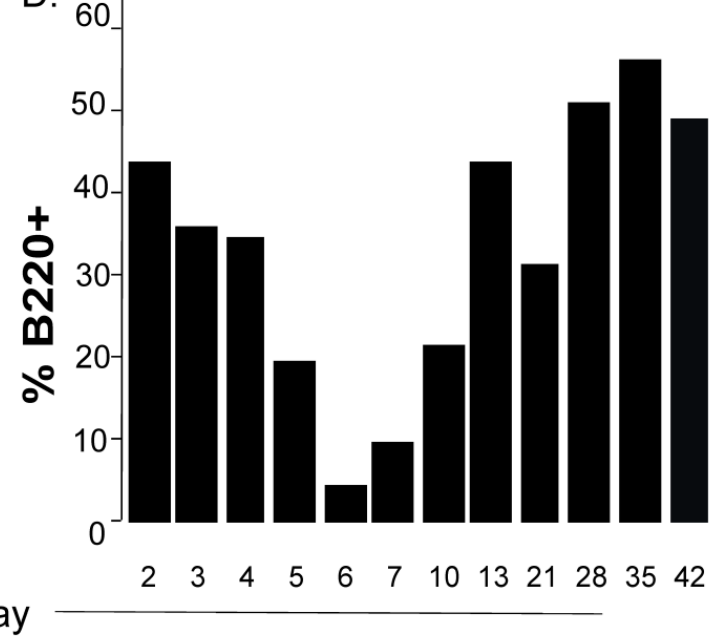

F.

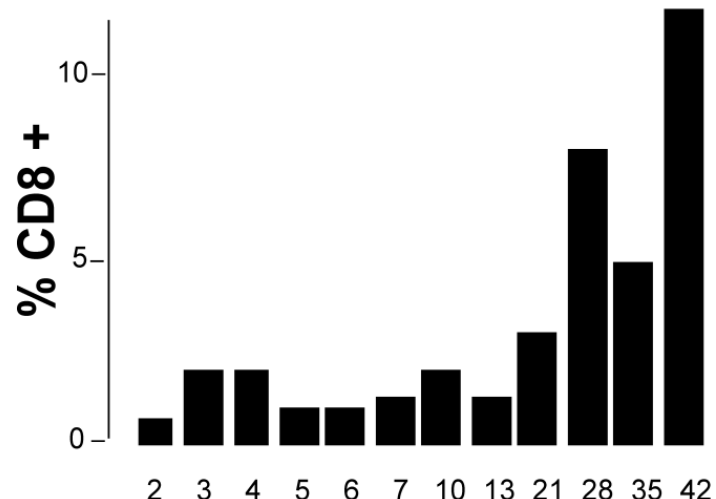

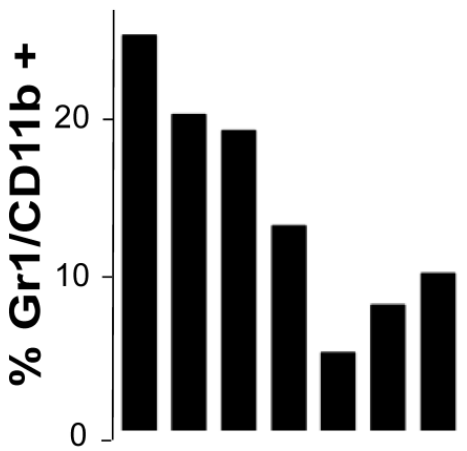

$\begin{array}{lllllll}2 & 3 & 4 & 5 & 6 & 7 & 10\end{array}$

day

Figure 3. The accumulation of immature erythroid cells compromises the representation of $T$ and $B$ cells in neonate spleens. (A, C, D, E and F) Flow cytometry analysis to determine the relative percentage of Ter I I9+ cells (A), CD4 T cells (C), CD8 T cells (D), B cells (B220) (E) and neutrophil/granulocytes (Grl) (F) in spleens from mice at different days after birth. Each bar in represents the mean of two mice and are representative of 2 experiments. (B) Relative percentages of Ter II9+ cells in spleen from mice at 7, 9, II and $2 \mathrm{I}$ days after birth. Error bars represent the standard error of the mean of at least four mice per group. Asterisk denotes a statistically significant $(p<0.05)$ decrease in the percentage of Terl I9+ cells between day 7 and day 9 , and between day 9 and 21 . Overall significance is at $\mathrm{p}<0.000 \mathrm{I}$. Analyses were performed by ANOVA with Newman-Keuls Multiple comparisons test. 
A.
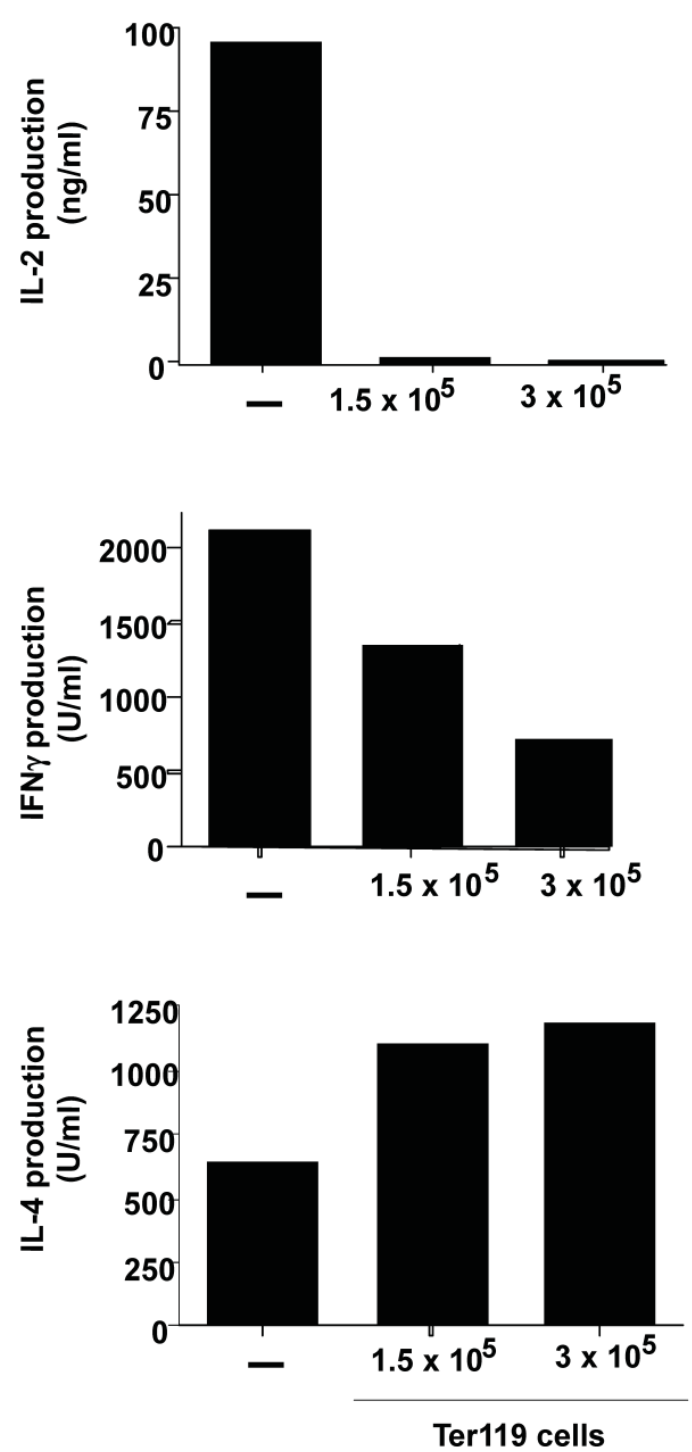

B.
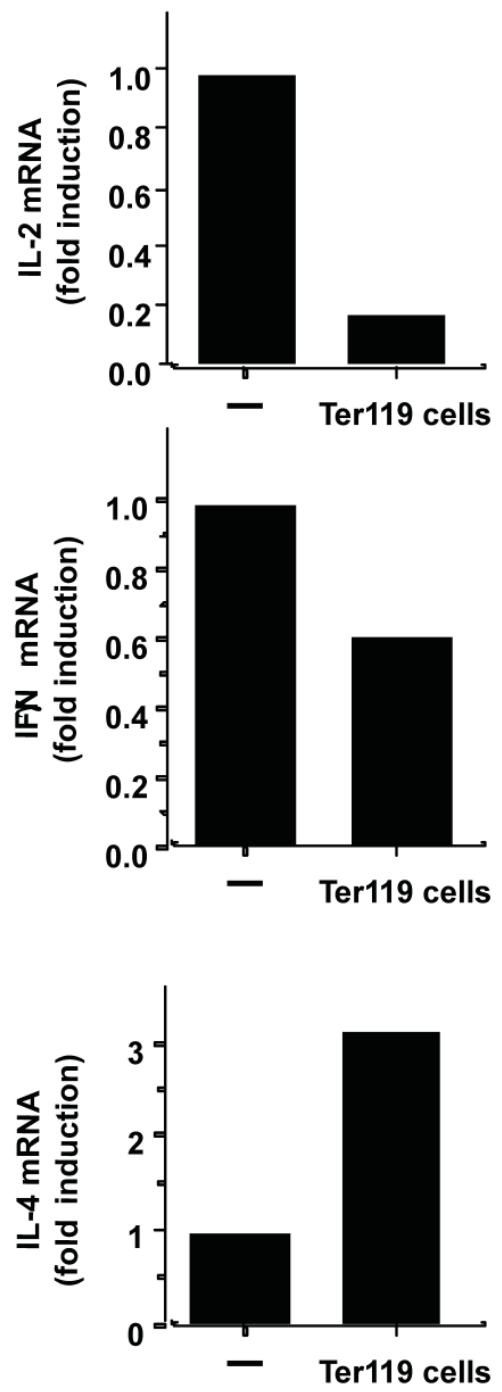

Figure 4. The presence of Ter I 19+ cells during the differentiation of CD4 T cells provides a Th2 bias. A. Purified adult CD4 T cells ( $10^{6}$ cells) were activated with anti-CD3 and anti-CD28 Abs for 3 days in the absence (-) or the presence of I.5 $\times 10^{5}$ or $3 \times$ 105 Terl 19+ cells from day-7 neonatal spleens. Cells were washed and equal number was restimulated with anti-CD3 Ab alone for $24 \mathrm{~h}$. Levels of IL-2, IFN $\gamma$, and IL-4 in supernatant were determined by ELISA. B. CD4 T cells were activated and restimulated as in (A) using I.5 $\times 10^{5}$ Terl I9+ cells. Relative levels of IL-2, IFN $\gamma$ and IL-4 mRNA were determined by real time RT-PCR. Fold induction relative to CD4 cells activated in the absence of Terl I 9 cells is shown. Data shown is representative of two experiments.

\section{Immature erythroid cells from neonatal spleen secrete IL-6.}

The exogenous cytokine milieu during the differentiation of naïve CD4 T cells into effector cells plays an important role in determining the fate of effector CD4 T cells and the type of cytokines these cells subsequently produce.

IL-4 is the main differentiation factor for Th2 effector cells, but the predominant source of IL-4 are
CD4 $\mathrm{T}$ cells themselves. We have shown that the proinflammatory cytokine IL-6 can promote Th2 bias by enhancing IL-4 production by CD4 T cells during their differentiation from naïve to effector cells [36],[37]. Since IL-6 can be produced by a number of cells outside of the immune system [38-45], we examined whether IL-4 expression during the differentiation of naïve CD4 $\mathrm{T}$ cells was also affected by the presence of neonatal immature erythroid cells. Adult CD4 $\mathrm{T}$ cells were activated in the presence or absence 
of nenonatal Ter $119^{+}$cells as described above and IL-4 expression was determined after 3 days of culture. Increased levels of IL- 4 were expressed by CD4 T cells activated in the presence of Ter $119^{+}$cells for three days (Figure 5A), suggesting that the increased production of IL-4 during the differentiation was the cause for the Th2 bias observed during restimulation (Figure 4). We therefore tested whether Ter119+ cells could provide IL- 6 to CD4 T cells and in turn promote IL-4 production by CD4 T cells. Analysis of IL-6 levels in the culture supernatant showed almost undetectable levels produced by CD4 T cells activated in the absence of Ter119+ cells (Figure 5B). However, high levels of IL-6 were present in cultures of CD4 cells activated in the presence of Ter119+ cells (Figure 5B).
A.

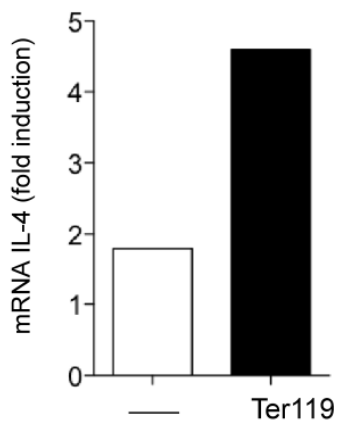

C.
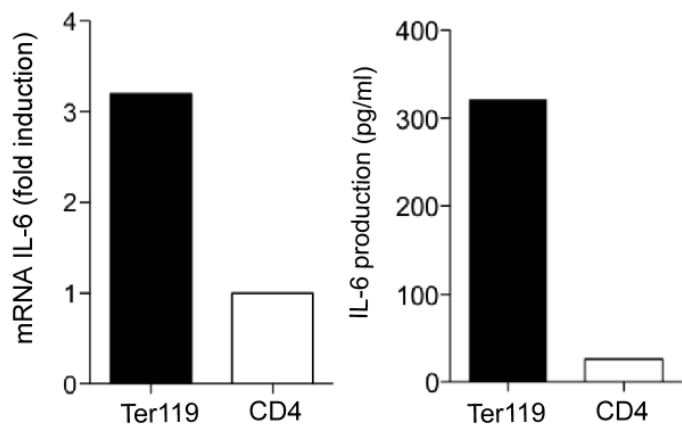

E.

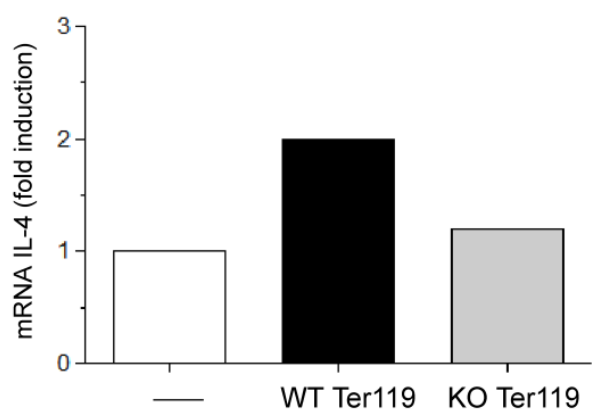

B.

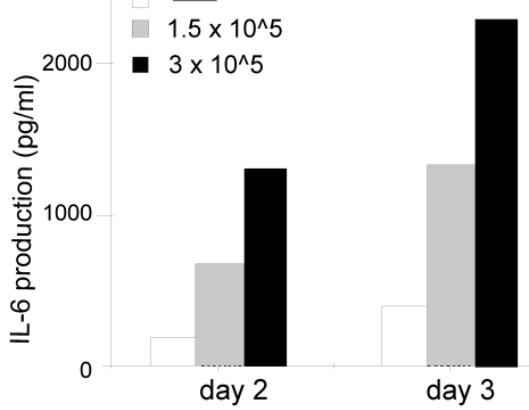

D.
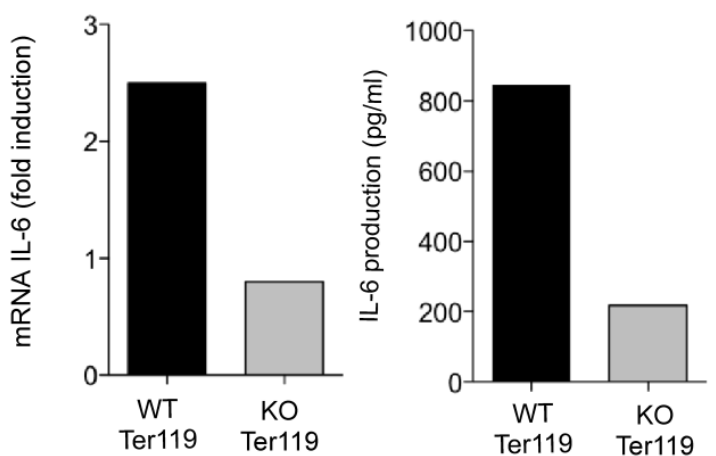

Figure 5. Neonate immature erythroid cells produce IL-6 during the co-culture with CD4 T cells. A. Relative IL-4 mRNA levels in adult CD4 T cells activated with anti-CD3 and anti-CD28 Abs in the absence (-) or presence (Ter I I9) of day-7 neonatal spleen Terl19+ cells $\left(3 \times 10^{5}\right)$ for 3 days, determined by real time RT-PCR. B. Purified adult CD4 T cells were activated with anti-CD3 and anti-CD28 Abs in the absence (-) or presence of the indicated number of neonatal spleen Terl I9+ cells for 2 or 3 days and IL-6 production in the supernatant was determined by ELISA. C. Day- 6 neonatal spleen Ter I 19+ cells were incubated in medium alone. Purified adult CD4 T cells were activated with anti-CD3 and anti-CD28 Abs. After $24 \mathrm{~h}$, relative levels of IL-6 mRNA (left panel) in both cultures were determined by real time RT-PCR, and IL-6 production in the culture supernatants (right panel) was determined by ELISA. D. Adult WT CD4 T cells were activated with anti-CD3 and anti-CD28 Abs in the presence of Terl 19+ cells isolated from WT (WT Ter I I9) or IL-6 $\mathrm{KO}$ (KO Terl I9) day 6-neonates. After $24 \mathrm{~h}$, relative levels of IL-6 mRNA (left panel) in both co-cultures were determined by real time RT-PCR, and IL-6 production in the co-culture supernatants (right panel) was determined by ELISA. E. Adult CD4 T cells were activated in the absence (-) and presence of Terl 19+ cells isolated from WT or IL-6 KO neonates for three days. Cells were washed and restimulated with anti-CD3 for $24 \mathrm{~h}$ and the relative IL-4 mRNA levels were determined by real time RT-PCR. Data shown is the mean of duplicate wells for each assay performed. 
To determine whether the immature erythroid cells could be a source of IL- 6 , we examined IL-6 gene expression in Ter119+ cells cultured alone or CD4 T cells cultured alone for one day. Analysis of mRNA shows levels of IL-6 mRNA in Ter119 cells substantially higher than in CD4 T cells. (Figure 5C, left panel). Moreover, analysis of IL-6 in culture supernatants from these cells by ELISA confirmed that Ter119+ cells were able to produce and secrete IL-6 (Figure 5C, right panel).

To further assess the contribution of IL- 6 derived from the immature erythroid cells to the overall IL-6 produced during the co-culture of these cells with CD4 T cells we used Ter119+ cells from IL-6 knockout (KO) mice. Wildtype (WT) CD4 T cells were activated in the presence of Ter $119^{+}$cells isolated from spleens of WT and IL-6 KO neonatal (day 6) mice. After twenty-four hours in culture, IL-6 mRNA levels were three-fold higher in co-cultures of CD4 T cells and WT Ter119+ cells as compared to co-cultures with IL-6 KO Ter119+ cells (Figure 5D, left panel). Similarly, higher levels of IL-6 were found in culture supernatants from CD4 T cells activated in the presence of WT Ter119+ cells compared with the levels of IL-6 in cultures with IL-6 KO Ter119+ cells (Figure 5D, right panel). Thus, immature erythroid cells represent the predominant source of IL-6 in these cultures.

Analysis of IL-4 expression upon restimulation of effector CD4 T cells from these co-cultures showed an upregulation of IL-4 in CD4 T cells that were differentiated in the presence of WT Ter $119^{+}$cells, but not in CD4 $\mathrm{T}$ cells that were differentiated in the presence of IL-6 KO Ter119+ cells (Figure 5E). Together, these results demonstrate that the immature erythroid cells transiently accumulating in the spleen of neonates have the ability to produce IL- 6 during activation of CD4 T cells and the presence of IL-6 helps to promote a bias towards IL-4 producing effector CD4 T cells.

\section{Discussion}

Current thinking is that the immune system of the neonate is unique compared to that of adults and even older children, and that more sophisticated approaches must be sought in order to achieve effective vaccination against exposure to infectious agents at this developmental stage. To that end, we believe the maturity or composition of tissues such as the lymph nodes and spleen are relevant targets for examination with regard to the development of early immunity. It is commonly known that the neonatal spleen is a "unique" or even "odd" organ. However, it is clear the spleen plays an important role in immunity [46]. In this study, we show that while the first 3-4 days after birth B cells and neutrophils seem to be the most representative populations, 6-7 days after birth there is a rapid and drastic accumulation of large nucleated erythroid cells bearing the Ter119 antigen that occupy most of the mouse spleen. We reason that the presence of these cells in the spleen is not likely for the purpose of prolongation of fetal hematopoiesis because the observed accumulation does not take place until several days after birth. Moreover we observed that their level of fetal hemoglobin is much lower than that found in fetal liver and that they express relatively higher amounts of adult hemoglobin.

Thus, during the life of neonates some kind of biological event must take place to trigger this spleen recruitment and/or expansion of these immature erythroid cells. These cells are slowly lost in the spleen during maturation of the neonates and by 4 weeks of age only $2-3 \%$ of spleen cells are represented by these Ter $119^{+}$cells. It is known that the frequency of Ter119+ erythroid cells can also be modulated at the adult stage during times of stress, for example infection $[47,48]$. It is likely that an environmental or hormonal factor such as those relating to food intake, socialization, or sexual maturation, influence the presence of these cells. Recently, it was found that injection of the T cell homeostatic factor IL-7 into mice increased erythrocyte precursors directly [49]. Moreover, another T cell homeostatic factor, IL-15 has also been shown to effect hematopoiesis [50]. It is possible that some of these factors contribute to the accumulation of immature erythroid cells in the spleen of neonates.

The proportional increase in these immature erythroid cells in the neonatal spleen approximately one week after birth is associated with a decrease in B and $\mathrm{T}$ cells. The decrease in the lymphocytic populations is probably due to the space limitation within the spleen, since the erythroid cells occupy most of the capacity of this organ. It is also possible that erythroid cells may "out compete" $\mathrm{T}$ and B cells for the same proliferative or homeostatic factors in the process of expansion. Histological analysis of spleen from day- 6 neonates showed a disrupted cell distribution with B and $T$ cell areas are no longer defined due to the homogenous distribution of nucleated erythroid cells (data not shown). The space limitation, disrupted organogenesis, and possible direct suppression by secreted factors [51] might account for the apparently impaired immune function reported in older data regarding neonates of this age. However, it is clear that these obstacles can be relatively overcome, with the outcome a skewing of the immune response $[9,10$, $16,18]$.

We show here for the first time that neonatal 
immature erythroid cells from the spleen can regulate CD4 $\mathrm{T}$ cell differentiation and the cytokine pattern produced. Our studies show that the presence of these neonatal immature erythroid cells during the activation of CD4 T cells leads to effector cells that produce reduced levels of IL-2 and IFN $\gamma$ (considered as Th1-type of cytokines), but instead produce increased levels of IL-4 (the prototype Th2 cytokine). Thus, the neonatal immature erythroid cells can alter the Th1/Th2 cytokine balance, and these cells may support a Th2 bias during neonatal development. A potential mechanism by which immature erythroid cells can modulate the CD4 T cell immune response is through the secretion of cytokines. Here we show that neonatal Ter119+ spleen cells produce IL- 6 and that this IL-6 contributes to the IL-4 upregulation in CD4 T cells when co-cultured. However, we do not rule out the participation of alternative mechanisms by which neonatal spleen erythroid cells can participate in effector CD4 T cell differentiation, such as by secretion of other cytokines as well as by physical interaction (e.g. adhesion molecules) with receptors/ligands on CD4 T cells. Moreover, these studies do not completely rule out the possible involvement of other cell types that might indirectly mediate the effects of Ter119+ cells on CD4 T cells.

In summary, we have identified here that neonatal immature erythroid cells have an immunomodulatory role in $\mathrm{CD} 4 \mathrm{~T}$ cell responses and that the massive presence of these cells in the spleen, selectively at several days after birth, could have a major impact in the overall immune response in neonates. Thus, the course of an immune response during infection or during vaccination of infants could be influenced by the presence of these immature erythroid cells. These studies underline the complex nature of the immune response in neonates and suggest future studies of the effects of Ter $119^{+}$cells on the function of other immune cells.

\section{Acknowledgements}

Financial Support: EAB is supported in part by RO1 HD043185. MRR is supported in part byPO1AI045666. This work is also supported by P20 RR021905-01- the Vermont Center for Immunology and Infectious Disease, P20 RR15557- the Vermont Lung Center, and the Departments of Medicine and Obstetrics, Gynecology, and Reproductive Sciences.

The authors would like to thank Roxanna Del Rio Guerra, Oliver Dienz and members of the Vermont Center for Immunology and Infectious Disease for useful discussions.

\section{Competing Interests}

The authors have declared that no competing interest exists.

\section{References}

1. Inter-agency Group for Child Mortaliaty Estimation. Levels and Trends in Child Mortality: Report 2010. UN. 2010.

2. Yorita KL, Holman RC, Sejvar JJ, Steiner CA, Schonberger LB. Infectious disease hospitalizations among infants in the United States. Pediatrics. 2008; 121(2): 244-52.

3. Lederberg J. Genes and antibodies. Science. 1959; 129(3364): 1649-53.

4. Adkins B, Chun K, Hamilton K, Nassiri M. Naive murine neonatal T cells undergo apoptosis in response to primary stimulation. J Immunol. 1996; 157(4): 1343-1349.

5. Ridge JP, Fuchs EJ, Matzinger P. Neonatal tolerance revisited: turning on newborn T cells with dendritic cells. Science. 1996; 271(5256): 1723-6.

6. Sun R, Wei H, Zhang J, Li A, Zhang W, Tian Z. Recombinant human prolactin improves antitumor effects of murine natural killer cells in vitro and in vivo. Neuroimmunomodulation. 2002; 10(3): 169-76.

7. Coffman RL, Mocci S, O'Garra A. The stability and reversibility of Th1 and Th2 populations. Cur Top Microbiol Immunol. 1999; 238: $1-12$.

8. Rose S, Lichtenheld M, Foote MR, Adkins B. Murine Neonatal CD4+ Cells Are Poised for Rapid Th2 Effector-Like Function. J Immunol. 2007; 178(5): 2667-2678.

9. Belnoue E, Fontannaz-Bozzotti P, Grillet S, Lambert P-H, Siegrist C-A. Protracted Course of Lymphocytic Choriomeningitis Virus WE Infection in Early Life: Induction but Limited Expansion of CD8+ Effector T Cells and Absence of Memory CD8+ T Cells. J Virol. 2007; 81(14): 7338-7350.

10. Forsthuber T, Yip HC, Lehmann PV. Induction of TH1 and TH2 immunity in neonatal mice. Science. 1997; 271: 1728-1730.

11. Caprio-Young JC, Bell JJ, Lee H-H, Ellis J, Nast D, Sayler G et al. Neonatally Primed Lymph Node, but Not Splenic T Cells, Display a Gly-Gly Motif within the TCR \{beta\}-Chain Complementarity-Determining Region 3 That Controls Affinity and May Affect Lymphoid Organ Retention. J Immunol. 2006; 176(1): 357-364.

12. Fadel SA, Cowell LG, Cao S, Ozaki DA, Kepler TB, Steeber DA et al. Neonate-primed CD8+ memory cells rival adult-primed memory cells in antigen-driven expansion and anti-viral protection. Int Immunol. 2006; 18(2): 249-257.

13. Sarzotti M, Robbins DS, Hoffman PM. Induction of Protective CTL Responses in Newborn Mice by a Murine Retrovirus. Science. 1996; 271(5256): 1726-1728.

14. Adkins B, Jones M, Bu Y, Levy RB. Neonatal tolerance revisited again: specific CTL priming in mouse neonates exposed to small numbers of semi- or fully allogeneic spleen cells. Eur J Immunol. 2004; 34(7): 1901-9.

15. Lequn L, Hyun-Hee L, Bell JJ, Randal KG, Jason SE, Andre G et al. IL-4 Utilizes an Alternative Receptor to Drive Apoptosis of Th1 Cells and Skews Neonatal Immunity toward Th2. Immunity (Science Direct). 2004; 20(4): 429-440.

16. Adkins B, Bu Y, Cepero E, Perez R. Exclusive Th2 Primary Effector Function in Spleens but Mixed Th1/Th2 Function in Lymph Nodes of Murine Neonates. J Immunol. 2000; 164(5): 2347-2353.

17. Adkins B, Du R-Q. Newborn Mice Develop Balanced Th1/Th2 Primary Effector Responses In Vivo But Are Biased to Th2 Secondary Responses. J Immunol. 1998; 160(9): 4217-4224.

18. Barrios C, Brawand P, Berney M, Brandt C, Lambert PH, Siegrist CA. Neonatal and early life immune responses to various forms of vaccine antigens qualitatively differ from adult responses: predominance of a Th2-biased pattern which persists after adult boosting. Eur J Immunol. 1996; 26(7): 1489-96.

19. Weaver CT, Hatton RD, Mangan PR, Harrington LE. IL-17 Family Cytokines and the Expanding Diversity of Effector T Cell Lineages. Ann Rev Immunol. 2007; 25(1): 821-852.

20. Burl S, Adetifa UJ, Cox M, Touray E, Ota MO, Marchant A et al. Delaying Bacillus Calmette-Guérin Vaccination from Birth to 4 1/2 
Months of Age Reduces Postvaccination Th1 and IL-17 Responses but Leads to Comparable Mycobacterial Responses at 9 Months of Age. J Immunol. 2010; 185(4): 2620-2628.

21. Kina T, Ikuta K, Takayama E, Wada K, Majumdar AS, Weissman IL et al. The monoclonal antibody TER-119 recognizes a molecule associated with glycophorin A and specifically marks the late stages of murine erythroid lineage. Brit J Haematol. 2000; 109(2): 280-287.

22. Coffman RL. Surface antigen expression and immunoglobulin gene rearrangement during mouse pre-B cell development. Immunological rev. 1982; 69: 5-23.

23. Coffman RL, Weissman IL. B220: a B cell-specific member of th T200 glycoprotein family. Nature. 1981; 289(5799): 681-3.

24. Kuhns MS, Davis MM, Garcia KC. Deconstructing the form and function of the TCR/CD3 complex. Immunity. 2006; 24(2): 133-9.

25. Kubo RT, Born W, Kappler JW, Marrack P, Pigeon M. Characterization of a monoclonal antibody which detects all murine alpha beta T cell receptors. J Immunol. 1989; 142(8): 2736-42.

26. Fleming TJ, Fleming ML, Malek TR. Selective expression of Ly-6G on myeloid lineage cells in mouse bone marrow. RB6-8C5 mAb to granulocyte-differentiation antigen (Gr-1) detects members of the Ly-6 family. J Immunol. 1993; 151(5): 2399-408.

27. Springer T, Galfre G, Secher DS, Milstein C. Mac-1: a macrophage differentiation antigen identified by monoclonal antibody. Eur J Immunol. 1979; 9(4): 301-6.

28. Gorgani NN, Ma Y, Clark HF. Gene signatures reflect the marked heterogeneity of tissue-resident macrophages. Immunology \& Cell Biology. 2008; 86(3): 246-54

29. Martin L, Douet V, VanWart CM, Heller MB, Le Saux O. A Mouse Model of [beta]-Thalassemia Shows a Liver-Specific Down-Regulation of Abcc6 Expression. Am J Pathol. 2011; 178(2): 774-783.

30. Wilkinson DG, Bailes JA, Champion JE, McMahon AP. A molecular analysis of mouse development from 8 to 10 days post coitum detects changes only in embryonic globin expression. Development. 1987; 99(4): 493-500.

31. Dienz O, Eaton SM, Bond JP, Neveu W, Moquin D, Noubade R et al. The induction of antibody production by IL-6 is indirectly mediated by IL-21 produced by CD4+ T cells. J Exp Med. 2009; 206(1): 69-78.

32. Diehl S, Chow C-W, Weiss L, Palmetshofer A, Twardzik T, Rounds L et al. Induction of NFATc2 Expression by Interleukin 6 Promotes T Helper Type 2 Differentiation. J of Exp Med. 2002; 196(1): 39-49.

33. Berenson RJ, Andrews RG, Bensinger WI, Kalamasz D, Knitter G, Buckner CD et al. Antigen CD34+ marrow cells engraft lethally irradiated baboons. J Clinical Invest. 1988; 81(3): 951-955.

34. Ikuta K, Weissman IL. Evidence that hematopoietic stem cells express mouse c-kit but do not depend on steel factor for their generation. Proc Nat Acad Sciences. 1992; 89(4): 1502-1506.

35. Spangrude G, Heimfeld S, Weissman I. Purification and characterization of mouse hematopoietic stem cells. Science. 1988; 241(4861): 58-62.

36. Diehl S, Anguita J, Hoffmeyer A, Zapton T, Ihle JN, Fikrig E et al. Inhibition of Th1 differentiation by IL- 6 is mediated by SOCS1. Immunity. 2000; 13(6): 805-15.

37. Dienz O, Rincon M. The effects of IL-6 on CD4 T cell responses. Clin Immunol. 2009; 130(1): 27-33.

38. Lockwood CJ, Murk WK, Kayisli UA, Buchwalder LF, Huang SJ, Arcuri $\mathrm{F}$ et al. Regulation of interleukin-6 expression in human decidual cells and its potential role in chorioamnionitis. Am J Pathol. 2010; 177(4): 1755-64.

39. De Benedetti F, Meazza C, Martini A. Role of interleukin-6 in growth failure: An animal model. Hormone Research. 2002; 58(SUPPL. 1): 24-27.

40. Neveu WA, Allard JB, Dienz O, Wargo MJ, Ciliberto G, Whittaker LA et al. IL-6 is required for airway mucus production induced by inhaled fungal allergens. J Immunol. 2009; 183(3): 1732-8.

41. Ahn KK, Kwon D, Jung K, Ha Y, Seo MJ, Kim S-H et al. Identification of interleukin-1, tumor necrosis factor-alpha, and interleukin-6 expression in lungs from pigs naturally infected with Mycoplasma hyopneumoniae by in situ hybridization. J Vet Med Sci. 2009; 71(4): 441-5.

42. Damm J, Luheshi GN, Gerstberger R, Roth J, Rummel C. Spatiotemporal nuclear factor interleukin-6 expression in the rat brain during lipopolysaccharide-induced fever is linked to sustained hypothalamic inflammatory target gene induction. J of Comparative Neurol. 2011; 519(3): 480-505

43. Kitajima T, Tajima Y, Kuroki T, Tsuneoka N, Adachi T, Kanematsu T. Interleukin-6 expression on the biliary epithelia during inflammation-associated biliary carcinogenesis in bilioenterostomized hamsters. J of Surgical Res. 2010; 162(1): 54-8.

44. Tseng W, Lu J, Bishop GA, Watson AD, Sage AP, Demer L et al. Regulation of interleukin-6 expression in osteoblasts by oxidized phospholipids. J Lipid Res. 2010; 51(5): 1010-6.

45. Zhang H, Jiang Z, Chang J, Li X, Zhu H, Lan HY et al. Role of $\mathrm{NAD}(\mathrm{P}) \mathrm{H}$ oxidase in transforming growth factor-beta1-induced monocyte chemoattractant protein-1 and interleukin-6 expression in rat renal tubular epithelial cells. Nephrology. 2009; 14(3): 302-10.

46. Brendolan A, Rosado MM, Carsetti R, Selleri L, Dear TN. Development and function of the mammalian spleen. Bioessays. 2007; 29(2): 166-77.

47. Jackson A, Nanton MR, O'Donnell H, Akue AD, McSorley SJ. Innate Immune Activation during Salmonella Infection Initiates Extramedullary Erythropoiesis and Splenomegaly. J Immunol. 2010; 185(10): 6198-6204.

48. MacNamara KC, Racine R, Chatterjee M, Borjesson D, Winslow GM. Diminished hematopoietic activity associated with alterations in innate and adaptive immunity in a mouse model of human monocytic ehrlichiosis. Infect Immun. 2009; 77(9): 4061-9.

49. Aiello FB, Keller JR, Klarmann KD, Dranoff G, Mazzucchelli R, Durum SK. IL-7 Induces Myelopoiesis and Erythropoiesis. J Immunol. 2007; 178(3): 1553-1563.

50. Mullarky IK, Szaba FM, Kummer LW, Wilhelm LB, Parent MA, Johnson LL et al. Gamma interferon suppresses erythropoiesis via interleukin-15. Infect Immun. 2007; 75(5): 2630-3.

51. Seledtsova GV, Seledtsov VI, Samarin DM, Senyukov VV, Ivanova IP, Akimenko ZA et al. Erythroid cells in immunoregulation: characterization of a novel suppressor factor. Immunol Lett. 2004; 93(2-3): 171-178 